\title{
Retroperitoneal Solitary Fibrous Tumor-Induced Hypoglycemia Associated with High Molecular Weight Insulin-Like Growth Factor II
}

\author{
Fumiko Yamakawa-Yokota, Nobuaki Ozaki, Akiko Okajima, Hideki Nishio, \\ Tetsuro Nagasaka and Yutaka Oiso
}

\begin{abstract}
A man, aged 65 years, presented with frequent episodes of hypoglycemia and unconsciousness. Hypoglycemia was accompanied by undetectable serum insulin and C-peptide levels and a high serum insulin-like growth factor (IGF)-Il level. He was found to have a retroperitoneal solitary fibrous tumor. He underwent successful resection of the tumor and had no hypoglycemic episodes after the operation. Immunohistochemical analysis revealed positive immunostaining for IGF-II in tumor cells. The presence of the high-molecular-weight form of IGF-II in the patient's serum was confirmed by immunoblotting, which suggests that his hypoglycemia was due to an increase in the plasma level of IGF-II secreted by the tumor.
\end{abstract}

Keywords: Insulin-like growth factor-II (IGF-II); Non-islet cell tumor hypoglycemia (NICTH);

Retroperitoneum; Solitary fibrous tumor

Corresponding Author:

Nobuaki Ozaki

Department of Endocrinology and Diabetes

Nagoya University Graduate School of Medicine

65 Tsurumai-cho, Showa-ku

Nagoya 466-8550, Japan

Tel: +8I-52-744-2I 42

Fax: $+8|-52-744-22| 2$

E-mail: n-ozaki@med.nagoya-u.ac.jp

Received: September 22, 2009

Revised: January 22, 2010

Accepted: February 3, 2010

doi: $10.3|2| / c m r .2010 .888$
A 1931 in a patient with a distinctive pleural lesion. ${ }^{1}$ Most of these tumors are located in the thoracic cavity, but their presence has been reported at numerous other sites, including the nasal cavity, ${ }^{2}$ upper respiratory $\operatorname{tract}^{3}$ and $\operatorname{liver}^{4}$; retroperitoneal solitary fibrous tumors, in contrast, are rare. ${ }^{5}$ Most solitary fibrous tumors are indolent and are inadvertently found in the course of examinations for other disorders. Some patients with solitary fibrous tumors are diagnosed with hypoglycemia due to secretion of insulin-like growth factor (IGF)-II by these tumor cells. ${ }^{6,7}$ Moreover, approximately $4 \%$ of solitary fibrous tumors are reported to be associated with hypoglycemia. ${ }^{8}$

Non-islet cell tumor hypoglycemia (NICTH) is rarely the cause of the hypoglycemia that is frequently associated with large tumors of mesenchymal or epithelial organs, such as solitary fibrous tumor, fibrosarcoma, mesothelioma, leiosarcoma, and hepatoma. ${ }^{9,10}$ It has been reported that the high molecular weight form of IGF-II secreted from the tumors plays an important role in the development of NICTH. ${ }^{9,10}$ When NICTH is caused by IGF-II production, the level of serum-free IGF-II is elevated, leading to suppression of the serum levels of growth hormone and IGF-I via negative feedback by IGF-II. Therefore, elevated levels of the high molecular weight form of IGF-II are useful for the diagnosis of this syndrome. We describe a case of NICTH caused by a retroperitoneal solitary fibrous tumor that secreted the high molecular weight form of IGF-II. 

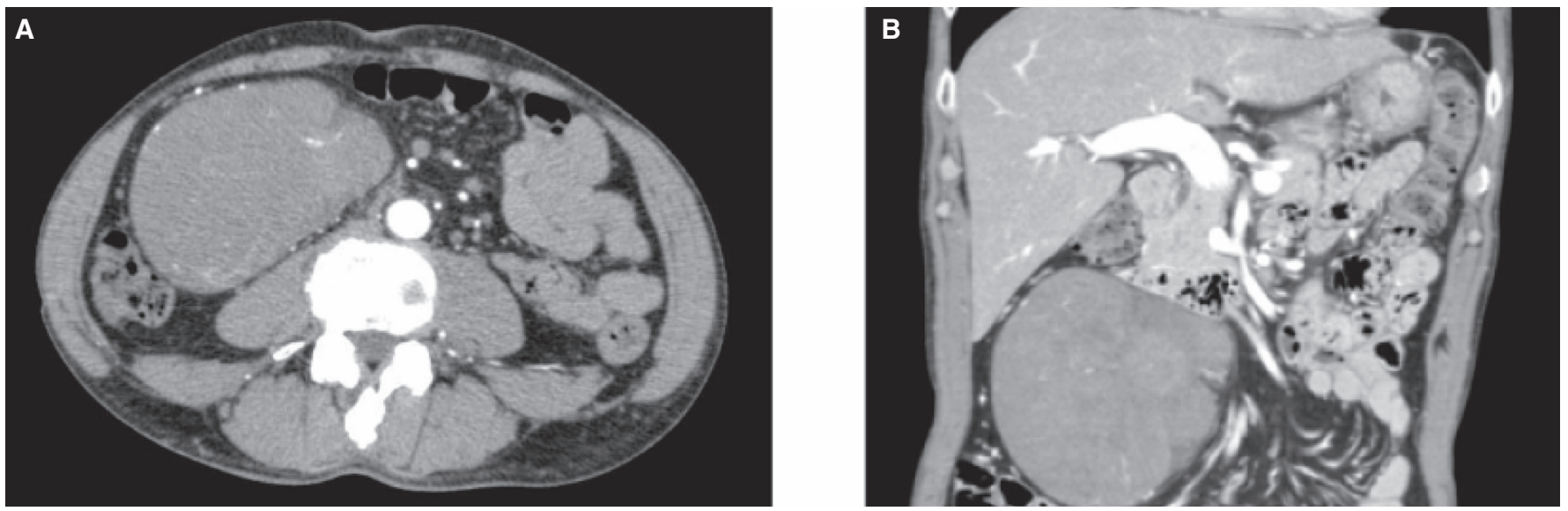

Figure 1. Contrast-enhanced CT scan of the abdomen, showing a large tumor located in the retroperitoneum: (A) sagittal section, (B) coronal section.

\section{Case Report}

In June 2008, a man, aged 65 years, was admitted to our hospital for hypoglycemia. He had experienced repeated episodes of hypoglycemia and loss of consciousness for a few months. He was not taking medication for hypoglycemia. The following data were recorded on admission: height, $170 \mathrm{~cm}$; weight, $60 \mathrm{~kg}$; blood pressure, 144/80 $\mathrm{mmHg}$; and pulse rate, 60 beats per minute. Physical examination revealed the presence of a large painless mass in the abdomen. Even though his fasting blood glucose level was $2.3 \mathrm{mmol} / \mathrm{L}$, his serum insulin and C-peptide levels were undetectable $(<2 \mathrm{U} /$ $\mathrm{mL}$ and $<0.1 \mathrm{ng} / \mathrm{mL}$, respectively). In addition, the counterregulatory hormone levels were relatively low. His thyroid, glucagon, and fasting cortisol levels were within the normal range (free T3, $2.39 \mathrm{pg} / \mathrm{mL}$; free T4, $0.93 \mathrm{ng} / \mathrm{dL}$; glucagon, $92 \mathrm{pg} / \mathrm{mL}$; cortisol, $13.6 \mathrm{~g} / \mathrm{dL}$ ). The serum growth hormone and IGF-I concentrations were relatively low $(0.31 \mathrm{ng} / \mathrm{mL}$ and $50.8 \mathrm{ng} / \mathrm{mL}$, respectively). We found hypokalemia (serum potassium, $2.3 \mathrm{mEq} / \mathrm{L}$ ). He tested negative for the anti-insulin antibody. Oral glucose tolerance testing showed a low serum insulin response. An abdominal computed tomography scan showed the presence of a large retroperitoneal tumor $(11 \mathrm{~cm} \times 11 \mathrm{~cm} \times 7 \mathrm{~cm})$ with a heterogeneous contrast effect (figure 1). On the basis of these findings, insulinoma, insulin autoimmune syndrome, and adrenal insufficiency were excluded as causative factors of the severe hypoglycemia, and NICTH as a result of the retroperitoneal tumor was suspected.

A glucose supplement of $15 \mathrm{~g} / \mathrm{h}$ was required to maintain the plasma glucose level within normal limits. Complete resection of the tumor was performed on June 24, 2008. The postoperative course was uneventful, and the glucose level stabilized thereafter. The resected tumor was $13 \mathrm{~cm} \times 13 \mathrm{~cm} \times 7$ $\mathrm{cm}$ in size and weighed $650 \mathrm{~g}$ (figure 2A). Microscopic examination showed admixed hypercellular and hypocellular foci of spindle-shaped cells encompassed by collagenous stroma (figure 2B). The resected tumor tissue was positive for CD34 but negative for epithelial membrane antigen, S-100, and desmin. Based on these findings, the pathological diagnosis of retroperitoneal solitary fibrous tumor was confirmed. The MIB-1 labeling index was $10 \%$, and 4 mitotic figures were observed per 10 high-power fields, suggesting the presence of a low-grade malignancy.

Immunohistochemical analysis showed positive immunostaining for IGF-II in the tumor cells (figure 2C). In addition, immunoblot analysis of IGF-II in the patient's preoperative serum extract revealed the presence of 2 distinct bands: a high molecular weight (approximately $15 \mathrm{kDa}$ ) band, and a low molecular weight $(7.5 \mathrm{kDa})$ band. Analysis of the control serum showed only a $7.5 \mathrm{kDa}$ band, corresponding to the size of normal IGF-II (figure 3). In the postoperative immunoblot analysis, the high molecular weight form of IGF-II disappeared, and the levels of serum IGF-II decreased from $2235 \mathrm{ng} / \mathrm{mL}$ to $1377 \mathrm{ng} / \mathrm{mL}$ (normal range, $414-1248 \mathrm{ng} / \mathrm{mL}$ ).

\section{Discussion}

Non-islet cell tumor hypoglycemia (NICTH) is one of the major causes of fasting hypoglycemia. It has been reported that NICTH develops as a result of the production of the high molecular weight form of IGF-II. ${ }^{9,10}$ Several mechanisms have been proposed for the hypoglycemia associated with NICTH caused by IGF-II production; according to one proposal, the hypoglycemia is caused by reduced secretion of growth hormone and elevated levels of free IGF-II. The serum levels of growth hormone and IGF-I are decreased even in the case of severe hypoglycemia. ${ }^{11}$ Insulin-like growth factor-II derived from the tumors may suppress growth hormone secretion at the pituitary level, leading to a reduction in the levels of circulating IGF-I. Impaired growth hormone response may account, in part, for the development of hypoglycemia. Thus, suppressed serum levels of growth hormone and IGF-I are useful diagnostic markers for IGF-II-producing NICTH. ${ }^{12}$ In the present case, the decreased serum levels of growth hormone and IGF-I were suggestive of an increase in the free IGF-II secreted by the tumor. In addition, hypokalemia was associated with hypoglycemia in NICTH. ${ }^{12}$ 

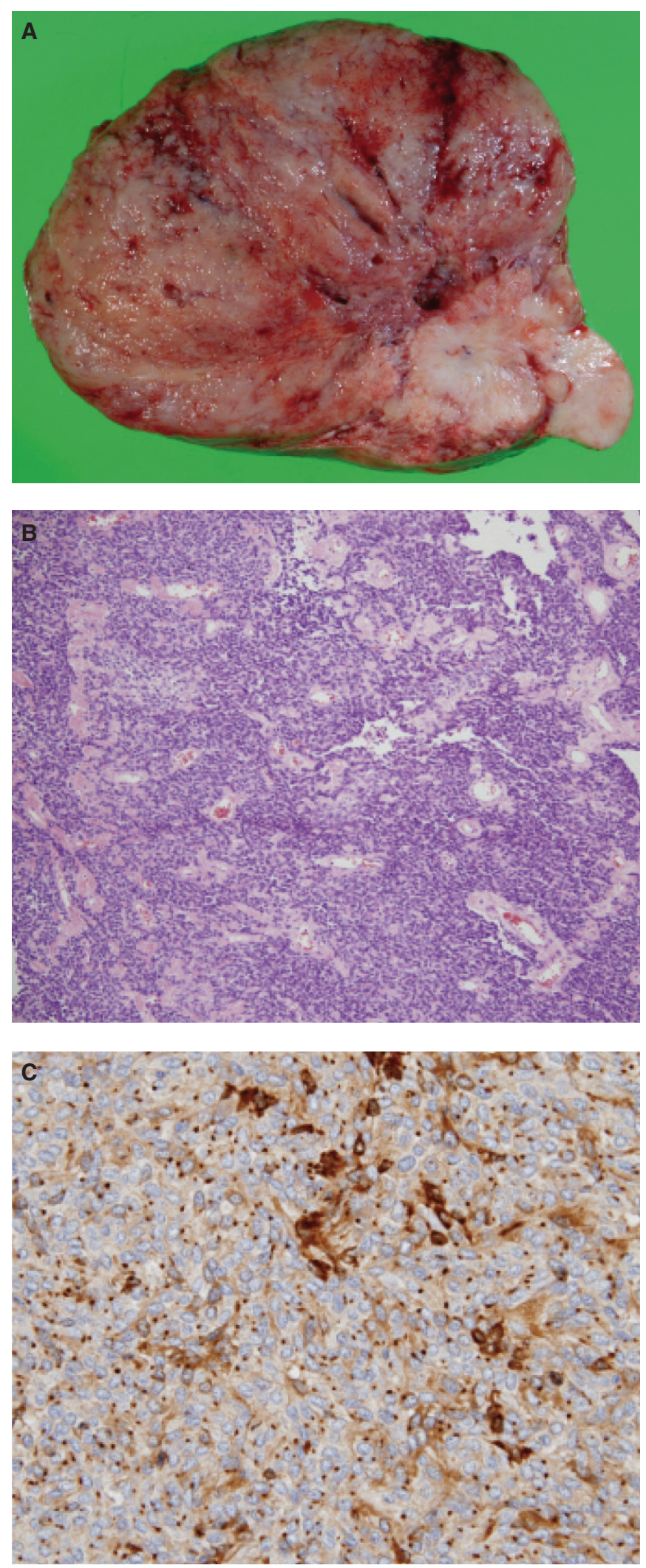

Figure 2. Resected retroperitoneal tumor. (A) Gross appearance. The tumor was believed to have originated from the retroperitoneum. (B) Microscopic appearance. Admixed hypercellular and hypocellular foci of spindle-shaped cells encompassed by collagenous stroma (HE stain, $\times 100)$. (C) Immunohistochemical staining of IGF-II. Many tumor cells were positive for the IGF-II antibody $(\times 400)$.
Although our patient had elevated serum IGF-II levels, serum IGF-II levels are not always elevated in patients with IGF-IIproducing NICTH. This inconsistency suggests that the unprocessed high molecular weight form, rather than the mature form, plays a pivotal role in the development of hypoglycemia. The high molecular weight form of IGF-II is considered to have greater bioavailability than mature IGF-II, supporting this idea. ${ }^{9,10}$ Under normal conditions, IGF-II binds to the IGF-binding protein-3 and an acid-labile subunit, forming a ternary complex of molecular weight $150 \mathrm{kDa}$. However, the high molecular weight form of IGF-II does not bind to the acid-labile subunit but to the IGF binding protein to form a $40-50 \mathrm{kDa}$ binary complex. ${ }^{9,10}$ This binary complex can pass through the capillary membranes and cause hypoglycemia via direct interaction with IGF and insulin receptors. Therefore, the diagnosis can be confirmed on the basis of increased serum IGF-II/IGF-I ratio or elevated levels of the high molecular weight form of IGF-II. ${ }^{12}$ In the present case, the preoperative serum IGF-II levels were elevated, and the IGF-II to IGF-I ratio was 43.9 (normal range, <10). In addition, preoperative western blot analysis revealed the presence of the high molecular weight form of IGF-II in the patient's serum, which is highly indicative of IGF-II-producing NICTH.

Solitary fibrous tumor is a relatively uncommon but distinctive mesenchymal neoplasm that frequently involves the pleura. ${ }^{1}$ Most solitary fibrous tumors are located in the thoracic cavity, but they have been reported at numerous other sites, including the nasal cavity, ${ }^{2}$ upper respiratory tract $^{3}$ and liver, ${ }^{4}$ as well as the retroperitoneum. ${ }^{5}$ However, the incidence of IGF-II-induced hypoglycemia in solitary fibrous tumors is still unclear. Briselli et $\mathrm{al}^{8}$ have reported that approximately $4 \%$ of solitary fibrous tumors that develop in the pleura are associated with hypoglycemia, while the incidence of hypoglycemia in the case of retroperitoneal solitary fibrous tumors has been reported to be approximately $11.5 \%{ }^{5}$ Although IGF production by retroperitoneal solitary fibrous tumors is generally implicated in hypoglycemia, ${ }^{13}$ increased IGF-II has been confirmed in only a few cases of these tumors. ${ }^{14}$ According to the previous reports with solitary fibrous tumors, the high molecular weight form of IGF-II was detectable in the serum of nine patients by western blot. Of those, retroperitoneal solitary fibrous tumors were present in only two patients..$^{15,16}$ In addition, the high molecular weight form was dominant in all nine cases. Thus, this is a rare case of hypoglycemia caused by a retroperitoneal solitary fibrous tumor with IGF-II production, confirmed by serum studies and immunohistochemistry.

Solitary fibrous tumors are typically benign in nature, with corresponding pathological findings, but malignant solitary fibrous tumors have frequently been reported. England et a $1^{17}$ reported that more than one-third of plural solitary fibrous tumors were histologically malignant in their group of patients, and they proposed pathological criteria for determining the malignancy of solitary fibrous tumors, such 


\section{$15 \mathrm{kDa}-$}

\section{$10 \mathrm{kDa}-$}

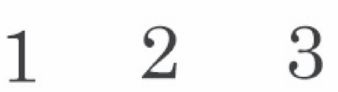

Figure 3. Immunoblot of serum IGF-II. Lane 1 and Lane 2 show the pre- and postoperative blots for the patient; Lane 3 shows the blot for the normal subject. Western blot analysis was performed with the anti-IGF-II antibody (Upstate Biochemistry), and high molecular weight IGF-II (15 kDa) was detected in the preoperative serum but was not detected in the postoperative serum.

as high cellularity and more than four mitotic figures per 10 high-power fields. Takizawa et $\mathrm{al}^{5}$ reported malignancy in $14.6 \%$ of patients with retroperitoneal solitary fibrous tumors. In the present case, a relatively high percent of MIB-1 labeling index and high mitotic activity were observed, indicating malignancy of the tumor. However, the clinical features of retroperitoneal solitary fibrous tumors are not necessarily concordant with the morphology, and most extrapleural solitary fibrous tumors in previous reports, even with malignant histological features, had benign behavior. ${ }^{6}$

In summary, we report a rare case of hypoglycemia associated with retroperitoneal solitary fibrous tumor. Based on the findings in this report, we think that the production of the high molecular weight form of IGF-II by the tumor caused the hypoglycemia. The presence of high serum levels of the high molecular weight form of IGF-II and elevated IGFII/IGF-I ratio strongly support the diagnosis of IGF-II-producing NICTH. Decreased serum levels of potassium, growth hormone and IGF-I are useful diagnostic markers for this syndrome. Furthermore, careful and long-term follow-up are required in the case of such patients, because behavior of solitary fibrous tumors is difficult to predict.

\section{References}

1. Klemperer P, Rabin LB. Primary neoplasm of the pleura: A report of five cases. Arch Pathol 1931;11:385-412.

2. Zukerberg LR, Rosenberg AE, Randolph G, Pilch BZ, Goodman ML. Solitary fibrous tumor of the nasal cavity and paranasal sinuses. Am J Surg Pathol 1991;15:126-130.

3. Witkin GB, Rosai J. Solitary fibrous tumor of the upper respiratory tract. A report of six cases. Am J Surg Pathol 1991; 15:842-848.

4. Chan G, Horton PJ, Thyssen S, Lamarche M, Nahal A, Hill DJ, Marliss EB, Metrakos P. Malignant transformation of a solitary fibrous tumor of the liver and intractable hypoglycemia. J Hepatobiliary Pancreat Surg 2007; 14:595-599.

5. Takizawa I, Saito T, Kitamura Y, Arai K, Kawaguchi M, Takahashi K, Hara N. Primary solitary fibrous tumor (SFT) in the retroperitoneum. Urol Oncol 2008;26:254-259.

6. Hasegawa T, Matsuno Y, Shimoda T, Hasegawa F, Sano T, Hirohashi S. Extrathoracic solitary fibrous tumors: their histological variability and potentially aggressive behavior. Hum Pathol 1999;30:1464-1473.

7. Mentzel T, Bainbridge TC, Katenkamp D. Solitary fibrous tumour: clinicopathological, immunohistochemical, and ultrastructural analysis of 12 cases arising in soft tissues, nasal cavity and nasopharynx, urinary bladder and prostate. Virchows Arch 1997;430:445-453.

8. Briselli M, Mark EJ, Dickersin GR. Solitary fibrous tumors of the pleura: eight new cases and review of 360 cases in the literature. Cancer 1981;47:2678-2689.

9. de Groot JW, Rikhof B, van Doorn J, Bilo HJ, Alleman MA, Honkoop AH, van der Graaf WT. Non-islet cell tumourinduced hypoglycaemia: a review of the literature including two new cases. Endocr Relat Cancer 2007;14:979-993.

10. Hizuka N, Fukuda I, Takano K, Asakawa-Yasumoto K, Okubo Y, Demura H. Serum high molecular weight form of insulinlike growth factor II from patients with non-islet cell tumor hypoglycemia is O-glycosylated. J Clin Endocrinol Metab 1998;83:2875-2877.

11. Ron D, Powers AC, Pandian MR, Godine JE, Axelrod L. Increased insulin-like growth factor II production and consequent suppression of growth hormone secretion: a dual mechanism for tumor-induced hypoglycemia. J Clin Endocrinol Metab 1989;68:701-706.

12. Fukuda I, Hizuka N, Ishikawa Y, Murakami Y, Sata A, Morita J, Kurimoto M, Okubo Y, Takano K. Clinical features of insulin-like growth factor-II producing non-islet-cell tumor hypoglycemia. Growth Horm IGF Res 2006;16:211-216.

13. de Perrot M, Fischer S, Brundler MA, Sekine Y, Keshavjee S. Solitary fibrous tumors of the pleura. Ann Thorac Surg 2002;74:285-293.

14. Wagner S, Greco F, Hamza A, Hoda RM, Holzhausen HJ, Fornara P. Retroperitoneal malignant solitary fibrous tumor of the small pelvis causing recurrent hypoglycemia by secretion of insulin-like growth factor 2. Eur Urol 2009;55:739-742.

15. Kageyama K, Moriyama T, Hizuka N, Sakihara S, Takayasu S, Tamasawa N, Suda T. Hypoglycemia associated with big insulin-like growth factor II produced during development of malignant fibrous histiocytoma. Endocr J 2003;50:753-758.

16. Kawashima A, Ujike T, Nin M, Nishimura K, Miyoshi S, Kawano K, Go Y, Kitaoka H. [A case of retroperitoneal solitary fibrous tumor associated with hypoglycemia.] [Article in Japanese] Hinyokika Kiyo 2009;55:395-399.

17. England DM, Hochholzer L, McCarthy MJ. Localized benign and malignant fibrous tumors of the pleura. A clinicopathologic review of 223 cases. Am J Surg Pathol 1989;13:640-658.

\section{Author Affiliations}

Fumiko Yamakawa-Yokota*; Nobuaki Ozaki*; Akiko Okajima '; Hideki Nishio';

Tetsuro Nagasakat; Yutaka Oiso*

*Department of Endocrinology and Diabetes, Nagoya

University Graduate School of Medicine, 65 Tsurumai-cho,

Showa-ku, Nagoya 466-8550, Japan

†Division of Surgical Oncology, Department of Surgery,

Nagoya University Graduate School of Medicine, 65

Tsurumai-cho, Showa-ku, Nagoya 466-8550, Japan

$\$$ Department of Clinical Pathology, Nagoya University

Graduate School of Medicine, 65 Tsurumai-cho, Showa-ku,

Nagoya 466-8550, Japan 